KLASNJA, S., S. Kopitovic and S. ORLOvic (2003): Variability of some wood properties of eastern cottonwood (Populus deltoides Bartr.) clones. Wood Sci. Tech. 37: 331-337.

KoubaA, A., R. E. Hernandez and M. Beaudoin (1998): Shrinkage of fast growing hybrid poplar clones. For. Prod. J. 48: 82-87.

Lieven, D. B., V. Dries, V. A. Joris and S. MARC (2007): End-use related physical and mechanical properties of selected fast-growing poplar hybrids (Populus trichocarpa $\times P$. deltoides). Ann. For. Sci. 64: 621-630.

O'NeIL, M. K., C. C. SHock and K. A. Lombard (2010): Hybrid poplar (Populus ssp.) selections for arid and semi-arid intermountain regions of the western United States. Agroforestry Syst 79: 409-418.

QIN, G. H., Y. Z. JIANG and Y. L. QIAO (2003): Study on the introduction of poplar S307-26 and PE-19-66 in Shandong Province. Journal of Jiangsu Forestry Science \& Technology 30(8): 1-6.

QIN, G. H., Y. Z. JIANG and Y. L. QIAO (2003): Field test of new poplar cones in Shandong Province. Journal of Forestry Research 14(3): 225-229.

RAJORA, O. P., L. ZsUFFA and F. C. YEH (1994): Variation, inheritance and correlations of growth characters and melampsora leaf rust resistance in full-sib families of Populus. Silvae Genetica 43 (4): 219-226.

REDEI, K. (2000): Early performance of promising white poplar (Populus alba) clones in sandy ridges between the rivers Danube and Tisza in Hungary. Forestry 73(4): 407-413.

Riemenschneider, D. E., B. E. McMahon and M. E. Ostry (1994): Population-dependent selection strategies needed for 2-year-old black cottonwood clones. Can J. For. Res. 24: 1704-1710.

SAS InSTITUE INC (1999): SAS/STAT user's guide, Version 8. SAS Institute Inc, Cary, NC, USA.

Steenackers, J., M. Steenackers, V. Steenackers and M. Stevens (1996): Poplar diseases, consequences on growth and wood quality. Biomass Bioenergy 10: 267-274.

YANG, S., L. LU and Y. Ni (2006): Cloned poplar as a new fiber resource for the Chinese pulp and paper industry. Pulp \& Paper Canada 107(2): 34-37.

Zhang, S. T., Q. B. Yu, G. Chauret and A. KoubaA (2003): Selection for both growth and wood properties in hybrid poplar clones. For. Sci. 49: 901-908.

Zobel, B. J. and J. B. JeTt (1995): Genetics of Wood Production. Springer Verlag, Berlin, Heidelberg, New York.

\title{
Crossability of Pinus sibirica and P. pumila with their hybrids
}

\author{
By G. V. VAsilyeva ${ }^{1)}$ and S. N. GoRoshkeViCH \\ Institute of Monitoring of Climatic and Ecological Systems, Siberian Branch of the Russian Academy of Sciences, \\ 10/3, Academichesky Ave., Tomsk, Russia
}

(Received $4^{\text {th }}$ June 2012)

\begin{abstract}
Crossability of Pinus sibirica and P. pumila hybrids and their parental species was studied using the controlled pollination method. Pinus sibirica and its hybrids were represented by grafts at the "Kedr" field station southeast of Tomsk Oblast, Russia; the parental species was of local provenance, with its hybrids obtained from the Southern Baikal region. In the case of $P$. pumila, trees were pollinated in a wild stand located in the Upper Angara River delta. Parental species had the highest number of filled seeds under open pollination. When they were pollinated with hybrid pollen, the trees showed nearly two-fold reductions in the number of filled seeds. Hybrids tended to abort most ovules during the first year of female cone development, resulting in a high seed abortion rate and consequent low seed production. The number of filled seeds obtained from hybrids was low, with levels ranging from 8.2 to $24.3 \%$. Because of weak reproductive isolation between hybrids and parental species, crosses are inevitable and lead to
\end{abstract}

1) Corresponding author: Galina Vasilyeva. Telephone: $+7(3822)$ 491907, Fax: +7(3822) 491950. E-mail: galina_biology@mail.ru species introgression. The hybrids probably contribute to interspecies genetic exchange both through hybrid seed production following pollination by parental species and by hybrid pollen distribution.

Key words: hybridization, Pinus sibirica, P. pumila, controlled pollination, reproductive isolation.

\section{Introduction}

Interspecies hybridization is common in plants, and quite frequently contributes to their evolution (RIESEBERG, 1997; RIESEBERG and CARNEY, 1998; ARNOLD et al., 1999). In woody plants, the widespread occurrence of natural hybridization is closely connected with anemophily, a non-specialized type of pollination (KoROPACHINSKIY and MILYUTIN, 1979; 2006). In conifers, natural hybridization usually leads to introgression, i.e., genetic exchange between species (GRANT, 1981; KoropaChINSKIY, 1992; KorOPACHINSKIY and MiLYUTIN, 2006).

Among five-needle pines, Siberian stone pine (Pinus sibirica Du Tour) and Siberian dwarf pine (P. pumila 
[Pall.] Regel) have the largest natural habitats, occupying about 5 and 6 million $\mathrm{km}^{2}$, respectively (CRITCHFIELD and LitTle, 1966). Pinus sibirica is widely distributed throughout Russia. Its northern border extends from the Izhma River to the middle course of the Pechora River and the Northern Urals, then east to the Yenisei River (up to $68^{\circ} \mathrm{N}$ ), and then slightly south to the upper reaches of the Aldan River. Its eastern border is in Transbaikalia, stretching along the Yablonovy Range into $P$. sibirica's southernmost point in northern Mongolia (about $46^{\circ} 30^{\prime} \mathrm{N}$ ). The southern border encompasses the Altai Mountains and extends westward to the southern part of the West Siberian Plain and thence to its western border in the Ural Mountains (Flora of USSR, 1934).

Pinus pumila is distributed between $69^{\circ}$ and $35^{\circ} \mathrm{N}$, i.e., from the northern timberline in Yakutia to Honshu Island. From west to east, its range extends from Lake Baikal to the Kamchatka Peninsula, although the middle portion of its western border deviates strongly to the east. This deviation is due to low snowfall in winter and the centuries-old impact of forest fires (UTKIN et al., 2001).

Pinus sibirica and $P$. pumila have extensively overlapping ranges, with areas of sympatry encompassing nearly 1 million $\mathrm{km}^{2}$ (Fig. 1). This overlapping territory includes the Aldan Uplands, the Stanovoye Uplands, the Vitim Plateau, the Khentei-Chikoiskoye Uplands, and the mountain ridges surrounding Lake Baikal, excluding its western shores.

Hybrids are frequently found in their parental species' communities. The effect of these hybrids on population processes is determined by their fertility and ability to backcross with parental species (GRANT, 1981; RIESEBERG, 2001). Controlled crossing experiments can be used to study reproductive isolation and estimate the strength of genetic barriers between species and/or hybrids. These crossing techniques have been widely applied to investigate affinity and incompatibility sources in conifers, especially in larches (AvROV, 1982), silver firs (KORMUTAK et al., 2008), spruces (FowLER, 1987; MAJOR et al., 2005), two-needle pines (McWILLIAM, 1959; CRITCHFIELD, 1966; WACHOWIAK et al., 2005; KoRMUTAK et al., 2005; LEWANDOWSKI and WISNIEWSKA, 2006), and five-needle pines (KRIEBEL, 1972; CRITCHFIELD, 1975; Titov, 1977; BladA, 1994; FERnANDO et al., 2005).

The earliest studies of natural hybridization between $P$. sibirica and $P$. pumila focused solely on morphology of a few putative hybrids (POZDNYAKOV, 1952; GALAZIY, 1954; MolOZHNIKOV, 1975). Hybridization between these species was confirmed by isoenzyme analysis (PoLITOV et al., 1999). Natural hybrids between $P$. sibirica and $P$. pumila are now known to frequently occur in areas where their habitats overlap (GoRosHKEvicH, 1999; Goroshkevich et al., 2008a,b). The hybrids are fertile, and are characterized by intermediate-sized cones and seeds and considerably reduced seed efficiency compared with the parental species (GoROSHKEVICH et al., 2008a). In previous studies, hybrid seed efficiency varied depending on terrain and year of collection, with $1.8-25.1 \%$ of ovules growing into filled seeds with welldeveloped embryos (GoRoshKEVICH, 2004; VASILYEVA et al., 2006; Petrova et al., 2007). When studying hybrid reproductive performance, knowledge of the degree of their reproductive isolation from parental species is needed to determine the intensity, direction, and probable results of hybridization. The aim of our study was to determine crossability of $P$. sibirica and $P$. pumila hybrids and their parental species using the controlled pollination method.

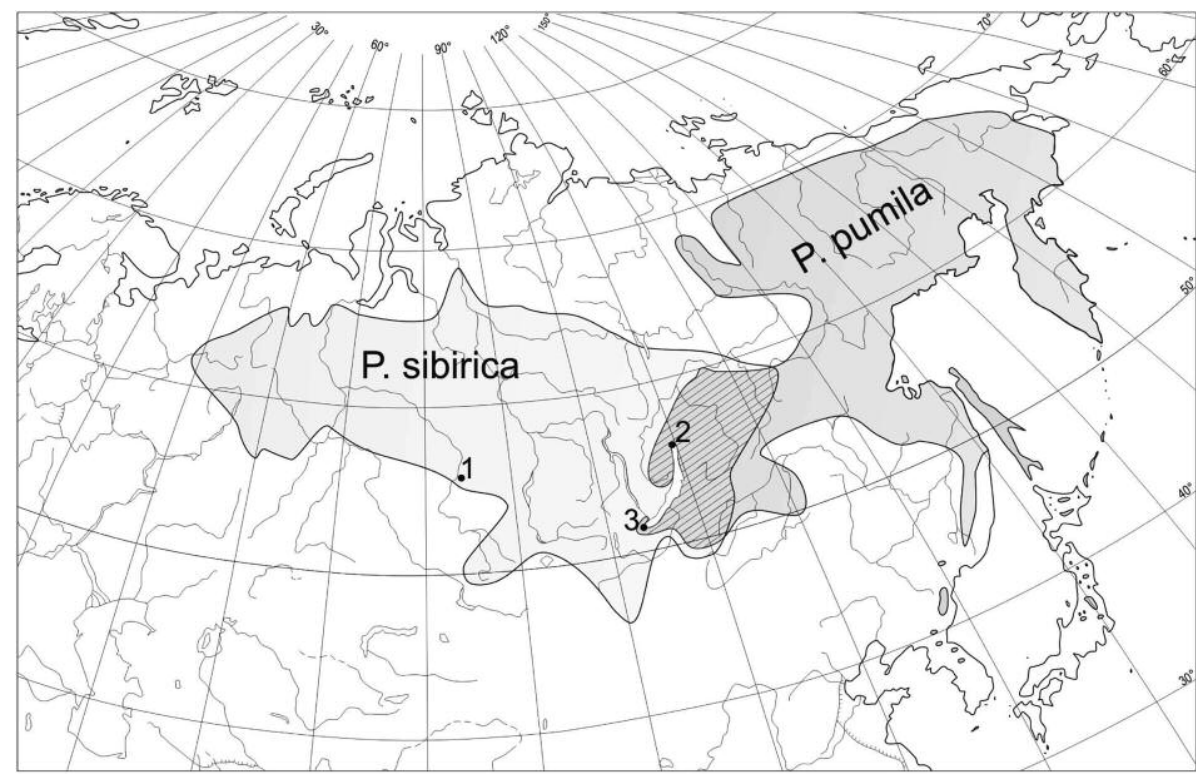

Figure 1. - Geographic distribution of P. sibirica and P. pumila. 1 - "Kedr" field station, 2 - Upper Angara River delta where controlled pollination of $P$. pumila was conducted, 3 - northern macroslope of Khamar-Daban Ridge is point of origin of hybrids used in the experiment. 


\section{Materials and Methods}

The study was carried out from 2005 to 2011 at two locations in Russia. The first location was the "Kedr" field station, managed by the Institute of Monitoring of Climatic and Ecological Systems and situated $30 \mathrm{~km}$ south of Tomsk ( $56^{\circ} 13 \mathrm{~N} 84^{\circ} 51 \mathrm{E}, 78 \mathrm{~m}$ above sea level). The second location was a wild stand of $P$. pumila in the Upper Angara River delta near Nizhneangarsk (55 $47 \mathrm{~N}$ $109^{\circ} 33 \mathrm{E}, 487 \mathrm{~m}$ above sea level). Grafts of eight $P$. sibirica clones of local provenance were used as maternal plants. For hybrid pollination, we used grafts represented by 11 hybrid clones originating from the northern macroslope of the Khamar-Daban Ridge (Fig. 1). Graftings were performed in 1997, with local $P$. sibirica trees used as rootstocks. Hybrid individuals were identified in the field based on tree habit and color of ripening cones. Compared with parental species, hybrids are intermediate in habit (GoROSHKEvicH et al., 2008a) and have purple cones of similar color to those of $P$. sibirica. All hybrids used in the study were presumed to be F1. We pollinated five $P$. pumila trees in the Upper Angara River delta, which were separated from one another by a distance of at least $50 \mathrm{~m}$ to ensure they were genetically distinct. Pinus sibirica pollen used in the experiment was a blend of pollen from several trees of local origin, while that of $P$. pumila was a blend from different trees in the wild stand in the Upper Angara River delta. Hybrid pollen was collected during the pollination year from the same grafts that were pollinated; only six clones were used because the remainder lacked microstrobili. Pinus sibirica pollen was collected a year prior to pollination, because pollen release in this species occurs slightly later than in cloned hybrids (VAsilyeva et al., 2010). Pinus pumila pollen was similarly collected beforehand, as $P$. pumila trees in the Upper Angara River delta release their pollen after that of $P$. sibirica and hybrids in the clonal archive. Collected pollen was stored below freezing, with calcium chloride used as a moisture absorbent.

For controlled pollination, female cones were isolated by placing Kraft paper bags over them approximately two days before pollen release. After isolation, we carefully observed the development of the covered cones, and pollinated them twice during their receptive phase. Paper bags were removed upon complete closure of cone scales.

The number of pollinated and measured cones varied each year over the course of the experiment, depending on the type of pollination. Only undamaged cones collected from 2006 to 2009 were measured, with seeds from the remaining cones saved for further analysis. Length, maximal diameter, and number of scales and seeds were measured for each cone. The number of potential ovules developing into formed seeds (both fullgrown and aborted) per cone, expressed as a percentage, was estimated using the formula

$$
S F F=\frac{N s e}{0.6 \times 2 N s c} \times 100 \%
$$

where $S F F$ is the seed formation frequency, Nse is the number of seeds, Nsc is the number of scales, and the coefficient 0.6 represents the average fraction of fertile scales in $P$. sibirica cones (GoROSHKEvich and KHUtoRnoy, 1996). Seeds were categorized as either full-grown or aborted, with the quality of full-grown seeds checked using X-ray analysis (SHCHERBAKOvA, 1965).

Collected data were statistically analyzed using Statistica 6.0 software. Mean, standard deviation, and maximum and minimum values were calculated. Comparison of means of cones taken from different crosses was performed using ANOVA and Duncan's post hoc test. We used the $\chi^{2}$ (chi-squared) test to compare proportions of filled seeds.

\section{Results}

During the year of pollination, conelet abortion under open pollination was minimal (around 10\%), with rates in hybrids and parental species differing only slightly. Under controlled pollination with hybrid pollen, conelet drop in the parental species increased to $40-50 \%$. Hybrids exhibited 40-50\% conelet abortion under controlled pollination, regardless of pollen source.

In both hybrids and parental species, mature cones retained their distinctive morphological features, regardless of pollination method; this was particularly apparent with respect to the number of scales (Table 1). No significant differences in cone length or diameter were observed, most likely because of the different numbers of full-grown seeds in cones. In regard to cone seed content, the presented cross variants differed from one another to varying extents, with the smallest values observed in the hybrids. The number of seeds in cones of parental species depended on pollen source, with reduced numbers observed when hybrid pollen was used.

Based on the estimated frequency of seed formation, open pollination was successful (Fig. 2). When parental species were pollinated by hybrid pollen, seed formation was initiated in ovules at levels approximately $75 \%$ of those observed under open pollination. Compared with parental species, the frequency of seed formation was quite low in hybrids. The highest value (54\%) was obtained upon pollination with $P$. sibirica, whereas the lowest recorded value (21\%) resulted from crossbreeding between hybrids. Both full-grown (normal size) and aborted (n-fold smaller) seeds were found in the cones. Under both open and controlled pollination, crosses involving parental species as maternal plants had seed abortion rates below $10 \%$. In contrast, the use of hybrids as maternal plants led to seed abortion rates of $25 \%$ or greater, with no significant differences observed with respect to cross type or pollen used (Fig. 2).

Analysis of full-grown seed quality revealed the presence of many empty seeds and seeds with undeveloped endosperm, regardless of cross type. The highest percentages of filled seeds were recorded from open-pollinated parental species and the lowest from hybrids, with intermediate values observed from parental species pollinated with hybrid pollen (Table 2 ). Seed quality varied from one year to the next, but relative proportions among the different crosses remained similar. Different 
Table 1. - Traits of Pinus sibirica (sib), P. pumila (pum) and their hybrids (hyb) cones obtained as a result of open $(\mathrm{OP})$ and controlled pollination.

\begin{tabular}{|l|l|c|c|c|c|c|c|c|c|}
\hline \multicolumn{2}{|c|}{ Trait } & sib OP & sib $\times h y b$ & hyb $\times$ sib & hyb $\times h y b$ & hyb OP & hyb $\times$ pum & pum $\times$ hyb & pum OP \\
\hline \multicolumn{2}{|c|}{ Number of measured cones } & 28 & 23 & 20 & 20 & 158 & 9 & 13 & 31 \\
\hline \multirow{3}{*}{ Cone length (mm) } & Mean & $65 \mathrm{a}$ & $62 \mathrm{a}$ & $45 \mathrm{~b}$ & $38 \mathrm{c}$ & $40 \mathrm{bc}$ & $43 \mathrm{bc}$ & $38 \mathrm{c}$ & $43 \mathrm{bc}$ \\
& Std.Dev. & 9 & 11 & 7 & 6 & 8 & 8 & 10 & 8 \\
& Min-Max & $46-86$ & $40-89$ & $31-55$ & $26-50$ & $17-55$ & $35-56$ & $29-59$ & $28-57$ \\
\hline \multirow{2}{*}{$\begin{array}{l}\text { Cone diameter } \\
\text { (mm) }\end{array}$} & Mean & $44 \mathrm{a}$ & $44 \mathrm{a}$ & $34 \mathrm{~b}$ & $30 \mathrm{c}$ & $31 \mathrm{c}$ & $32 \mathrm{bc}$ & $27 \mathrm{~d}$ & $30 \mathrm{c}$ \\
& Std.Dev. & 5 & 6 & 4 & 4 & 5 & 4 & 7 & 3 \\
\hline \multirow{3}{*}{ Number of scales } & Min-Max & $35-52$ & $36-55$ & $27-39$ & $22-37$ & $18-40$ & $27-39$ & $16-40$ & $25-35$ \\
\hline \multirow{3}{*}{ Number of seeds } & Mean & $85 \mathrm{a}$ & $84 \mathrm{a}$ & $55 \mathrm{~b}$ & $56 \mathrm{~b}$ & $54 \mathrm{~b}$ & $56 \mathrm{~b}$ & $45 \mathrm{c}$ & $42 \mathrm{c}$ \\
& Std.Dev. & 8 & 11 & 6 & 6 & 8 & 8 & 9 & 6 \\
& Min-Max & $67-102$ & $50-97$ & $47-67$ & $43-67$ & $36-83$ & $43-63$ & $35-62$ & $30-50$ \\
\hline \multirow{2}{*}{$\begin{array}{l}\text { Number of full- } \\
\text { grown seeds }\end{array}$} & Mean & $76 \mathrm{a}$ & $52 \mathrm{~b}$ & $36 \mathrm{c}$ & $14 \mathrm{e}$ & $20 \mathrm{de}$ & $27 \mathrm{~cd}$ & $23 \mathrm{~d}$ & $35 \mathrm{c}$ \\
& Std.Dev. & 17 & 20 & 15 & 11 & 11 & 12 & 21 & 16 \\
& Min-Max & $34-104$ & $14-94$ & $7-60$ & $3-45$ & $2-67$ & $8-49$ & $1-63$ & $11-66$ \\
\hline
\end{tabular}

Note: for a given variable, means not followed by the same letter are significantly different $(p \leq 0.05)$.

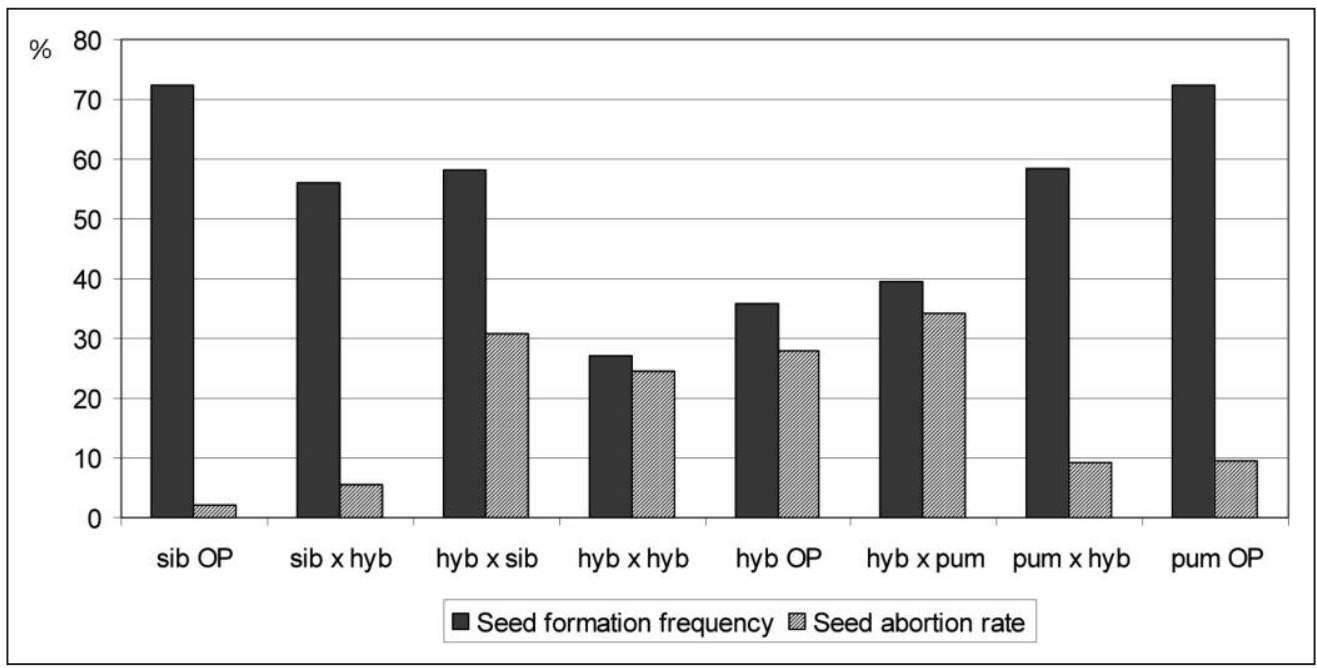

Figure 2. - Seed formation frequency and seed abortion rate in different crosses. Designation of cross types is the same as in the tables.

pollination schemes gave rise to different percentages of filled seeds. Chi-squared tests found significant differences $(p<0.001)$ in filled seed percentages among all but two pairs of crosses. There were no significant differences between the backcrosses $P$. sibirica $\times$ hybrids and $P$. pumila $\times$ hybrids $(p=0.161)$, or between crosses where hybrids were maternal plants, i.e., hybrids $\times$ hybrids vs. hybrids $\times P$. pumila $(p=0.302)$. We also examined the quality of seeds from hybrid cones. Throughout the study period, hybrids, regardless of cross type, tended to have nearly identical small numbers of filled seeds. In 2011, however, the number of filled seeds obtained from open-pollinated hybrids was lower than the number derived from hybrids under controlled pollination. 
Table 2. - Seed quality of Pinus sibirica (sib), hybrids (hyb) and P. pumila (pum) under open (OP) and controlled pollination in different years.

\begin{tabular}{|c|c|c|c|c|c|c|c|c|}
\hline Cross type & $s i b$ OP & sib $\times h y b$ & $h y b \times s i b$ & $h y b \times h y b$ & $h y b$ OP & hyb $\times p u m$ & pum $\times h y b$ & pum $\mathrm{OP}$ \\
\hline \multicolumn{9}{|c|}{2006} \\
\hline Number of analyzed seeds & 270 & 103 & 150 & -1 & 495 & - & - & - \\
\hline Number of filled seeds & 189 & 51 & 30 & - & 100 & - & - & - \\
\hline Percentage of filled seeds & 70.0 & 49.5 & 20.0 & - & 20.2 & - & - & - \\
\hline \multicolumn{9}{|c|}{2007} \\
\hline Number of analyzed seeds & - & 350 & 799 & - & 1533 & 116 & - & - \\
\hline Number of filled seeds & - & 216 & 38 & - & 113 & 12 & - & - \\
\hline Percentage of filled seeds & - & 61.7 & 4.8 & - & 7.4 & 10.3 & - & - \\
\hline \multicolumn{9}{|c|}{2008} \\
\hline Number of analyzed seeds & - & 245 & 105 & 59 & - & 77 & - & - \\
\hline Number of filled seeds & - & 94 & 18 & 11 & - & 22 & - & - \\
\hline Percentage of filled seeds & - & 38.4 & 17.1 & 18.6 & - & 28.5 & - & - \\
\hline \multicolumn{9}{|c|}{2009} \\
\hline Number of analyzed seeds & 612 & 582 & - & 164 & 712 & 81 & 264 & 852 \\
\hline Number of filled seeds & 430 & 205 & - & 17 & 103 & 3 & 95 & 691 \\
\hline Percentage of filled seeds & 70.3 & 35.2 & - & 10.4 & 14.5 & 3.7 & 36.0 & 81.1 \\
\hline \multicolumn{9}{|c|}{2011} \\
\hline Number of analyzed seeds & - & 517 & - & 211 & 824 & 199 & - & - \\
\hline Number of filled seeds & - & 162 & - & 65 & 159 & 78 & - & - \\
\hline Percentage of filled seeds & - & 31.3 & - & 30.8 & 19.3 & 39.2 & - & - \\
\hline \multicolumn{9}{|c|}{ Total } \\
\hline Number of analyzed seeds & 882 & 1797 & 1054 & 434 & 3564 & 473 & 264 & 852 \\
\hline Number of filled seeds & 619 & 728 & 86 & 93 & 475 & 115 & 95 & 691 \\
\hline Percentage of filled seeds & $70.2 \mathrm{~b}^{2}$ & $40.5 \mathrm{c}$ & $8.2 \mathrm{f}$ & $21.4 \mathrm{~d}$ & $13.3 \mathrm{e}$ & $24.3 \mathrm{~d}$ & $36.0 \mathrm{c}$ & 81.1 a \\
\hline
\end{tabular}

Note: ${ }^{1}$ - given crosses are not conducted in this study year.

${ }^{2}$ - values not followed by the same letter are significantly different $(p \leq 0.05)$.

\section{Discussion}

With respect to cross pollination of hybrids and parental species, incompatibility obviously plays a major role in seed efficiency. It is commonly believed that incompatibility manifests itself at every stage of seed development, whether during pollen germination or embryo development. This is clearly observed in deceleration of all development processes along with their association failures (BANNIKOVA, 1986; JoHNSON, 2010). Fiveneedle pine cones develop over two growing seasons. During the first year of cone development, pollination takes place, with pollen subsequently germinating and pollen tubes growing into the nucellus. The following year, the female gametophyte begins growing intensively; the megaspore, archegonia, and ovules are formed, and fertilization and embryo development then occur (Ferguson, 1901; NeKrasova, 1972; Owens and Molder, 1977). In five-needle pines, incompatibility manifests itself during the second year of cone development, and is usually evidenced by fertilization failure or rapid deteri- oration of the newly formed embryo (HAGMAN and MiKKOLA, 1963; KRIEBEL, 1972; FERNANDO et al., 2005).

Low seed formation frequency is typical in cross-pollinating species, including $P$. sibirica and $P$. pumila (WIENS, 1984). In our study, we discovered that a significant number of ovules, both in parental species and hybrids, died during the year of pollination. Although it is surprising that parental species lost a third to a half of ovules (depending on the pollination method), hybrid losses were much higher, i.e., three-fourths. This fact clearly indicates the inferiority of most hybrid ovules, namely, their inability to develop into well-formed embryo-containing seeds. As evidenced by incompatibility, maternal genotype, rather than interaction of male and female reproductive systems, is therefore the most important factor influencing hybrid seed efficiency. Some pine species, for example $P$. sylvestris (KÄRKKÄINEN et al., 1999) and $P$. sibirica (GoROSHKEVICH and KHUTORNOY, 1996) in their non-hybridizing populations, have individuals with genetically conditioned low seed 
efficiency. Low seed efficiency is apparently the norm in $P$. sibirica and $P$. pumila hybrids rather than the exception.

CRITCHFIELD (1975) suggested that the magnitude of genetic barriers between two species can be expressed by crossability, i.e., the percentage ratio of number of germinable seeds from crosses between two species to the number of seeds from within-species crosses. In a similar fashion, crossability between parental species and hybrids can be represented as the percentage ratio of the number of filled seeds in a cone from species pollinated by hybrid pollen to the same number from openpollinated species. The number of filled seeds in a cone can be obtained by multiplying the proportion of filled seeds (Table 2) by the number of full-grown seeds (Table 1). Based on these calculations, the crossability of maternal parents $P$. sibirica and $P$. pumila with hybrids were $38.2 \%$ and $28.6 \%$, respectively. Considering that crossability values can vary from 0 to $100 \%$, the calculated values are lower than average, but are typical for most compatible Pinus species (CRITCHFIELD, 1975). It is also worth mentioning that while five attempts were made to cross $P$. sibirica with hybrids, only one experiment was performed between $P$. pumila and hybrids. To confirm the values obtained in this study, additional crossing attempts must thus be made between $P$. pumila and its hybrids.

When hybrids were backcrossed with parental species (hybrids $\times P$. sibirica and hybrids $\times P$. pumila), the number of filled seeds was never high (averaging 8.2 and $24.3 \%$, respectively). In addition, crosses between two hybrids were not useful as controls, as the resulting number of filled seeds was lower than those obtained from the crosses between hybrids and $P$. pumila. It was furthermore difficult to differentiate between influences due to incompatibility vs. those arising from poor hybrid ovule quality.

The results of our study demonstrate that reproductive isolation of hybrids from their parental species is weak and cannot prevent them from crosses, thus leading to introgression. Absence of total reproductive isolation between hybrids and their parental species is common among many other hybridizing Pinus species (LEDIG, 1998). Of many examples, introgression is typical for $P$. sylvestris and $P$. uncinata (JASINSKA et al., 2010), P. taeda and P. echinata (CHEN et al., 2004), $P$. contorta and $P$. banksiana (CRITCHFIELD, 1985), P. montezumae and P. hartwegii (MATOS and SCHAAL, 2000), and P. pumila and P. parviflora (SENJO et al., 1999).

Despite the great variability observed during the course of the study in the number of filled seeds obtained from crosses between hybrids and their parental species, we found that hybrids and $P$. pumila have greater crossability than hybrids and $P$. sibirica. This observation is corroborated by the results of a genetic study of natural hybrids and their parental species in the Baikal region. In that study, hybrids whose embryos were formed primarily by pollination with $P$. sibirica pollen had twice as many empty seeds, and four times more seeds with undeveloped endosperm, than hybrids pollinated by $P$. pumila (PETRova et al., 2007). In all probability, hybrids cross better with their maternal parental species, meaning that the observed superior crossability is nothing more than a maternal effect. To prove this hypothesis and define the genetic contribution of each individual hybrid genotype for each species, additional studies are required.

In conclusion, controlled pollination of $P$. sibirica and P. pumila hybrids and their parental species was carried out for the first time in our study. Our results demonstrate that pollination of parental species by hybrid pollen led to considerably decreased seed efficiency. Low seed efficiency in the hybrids is due to their genetic character, with some ovules unable to develop into sound seeds. As a consequence, weak reproductive isolation between hybrids and their parental species can lead to introgression. This introgression can be bidirectional because of reciprocal back crossing between hybrids and their parental species.

\section{Acknowledgements}

This study was supported by the Siberian branch of the Russian Academy of Sciences (Project No. VI.52.2.6 and Integration Project No. 140) and the Russian Foundation for Basic Research (Project No. 12-04-31340).

\section{References}

Arnold, M. L., M. R. Bulger, J. M. Burke, A. L. Hempel and J. H. Williams (1999): Natural hybridization: how low can you go and still be important? Ecology 80: 371-381.

Avrov, F. D. (1983): Crossability of different larch species in collection maternal plantation in Siberia. Lesovedenie 5: 23-30. (In Russian)

BANNIKovA, V. P. (1986): Interspecies incompatibility of plants. Naukova dumka, Kiev. (In Russian)

BLADA, I. (1994): Interspecific hybridization of Swiss stone pine (Pinus cembra L.). Silvae Genet. 43: 14-20.

Chen, J., C. G. Tauer, G. Bai, Y. Huang, M. E. Payton and A. G. Holley (2004): Bidirectional introgression between Pinus taeda and Pinus echinata: evidence from morphological and molecular data. Can. J. For. Res. 34: 2508-2516.

CRITCHFIELD, W. B. (1966): Crossability and relationships of the closed-cone pines. Silvae Genet. 16: 89-97.

CRITChField, W. B. (1975): Interspecific hybridization in Pinus: a summary review, pp. 99-105. In: Symp. on Interspecific and Interprovenance Hybridization in Forest Trees, edited by D. P. Fowler, C. Y. Yeatman. Proc. $14^{\text {th }}$ Meeting, Canad. Tree Improv. Assoc., Part II.

CRITChFIELD, W. B. (1985): The late Quaternary history of lodgepole and jack pines. Can. J. For. Res. 15: 749-772.

CRitchfield, W. B. and E. L. LitTle (1966): Geographic Distribution of the pines of the world. USDA Forest Service, Washington, DC. Miscellaneous Publication 991.

Ferguson, M. C. (1901): The development of the egg and fertilization in Pinus strobus L. Ann. Bot. 15: 435-479.

FERnando, D. D., S. M. Long and R. A. SNiezko (2005): Sexual reproduction and crossing barriers in white pines: the case between Pinus lambertiana (sugarpine) and P. monticola (western white pine). Tree Genetics and Genomes 1: 143-150. 
FLORA of USSR by editing V. L. KOMAROV (1934): USSR Academy of Science, Leningrad. 302 p. (In Russian)

Fowler, D. P. (1987): The hybrid white $\times$ Sitka spruce: species crossability. Can. J. For. Res. 17: 413-417.

GALAZIY, G. I. (1954): Timberline flora in the mountains of Eastern Siberia and its dynamics. Proceedings of Botanical Institute, USSR Academy of Science 3(9): 210-329. (In Russian)

Goroshkevich, S. N. (2004): Natural hybridization between Russian stone pine (Pinus sibirica) and Japanese stone pine (Pinus pumila), pp. 169-171. In: Breeding and genetic resources of five-needle pines: growth, adaptability, and pest resistance. Proceedings of the IUFRO Five-Needle Pines Working Party Conference, July 23-27, 2001, Medford, Oregon, USA.

GoroshKevich, S. N. (1999): On the possibility of natural hybridization between Pinus sibirica and Pinus pumila in the Baikal Region. Botanicheskij Journal 84(9): 48-57. (In Russian)

Goroshkevich, S. N. and O.V. Khutornoy (1996): Intrapopulation diversity of Pinus sibirica Du Tour cone and seed. Report 1. Level and character of trait variability. Rastitelnye resursy 32(3): 1-12. (In Russian)

Goroshkevich, S. N., A. G. Popov and G. V. VAsilieva (2008): Ecological and morphological studies in the hybrid zone between Pinus sibirica and Pinus pumila. Ann. For. Res. 51: 43-52. (a)

Goroshkevich, S. N., G.V. Vasilyeva and A. G. Popov (2008): On hybridization Siberian stone pine and Siberian dwarf pine in the western part of Stanovoe nagorye. Lesnoe khozyaystvo 6: 25-27. (In Russian) (b)

GranT, V. (1981): Plant speciation. Columbia University Press, New York.

Hagman, M. and L. Mikkola (1963): Observations on cross-, self- and interspecific pollinations in in Pinus peuce Griseb. Silvae Genet. 12: 73-79.

JASIŃSKA, A. K., W. WACHOWIAK, E. MUCHEWICZ, K. Boratińska, J. M. Montserrat and A. Boratinsk (2010): Cryptic hybrids between Pinus uncinata and P. sylvestris. Botanical Journal of the Linnean Society 163: $473-485$

Johnson, N. A. (2010): Hybrid incompatibility genes: remnants of a genomic battlefield? Trends in Genetics 26 317-325.

KÄRKKÄINEN, K., O. SAVOLAINEN and V. Koski (1999): Why do plants abort so many developing seeds: bad offspring or bad maternal genotypes? Evolutionary Ecology 13: 305-317.

Kormuták, A., S.-W. LeE, K.-N. Hong, B.-H. YANG and Y.-P. HoNG (2008): Crossability relationships between Korean firs Abies koreana, A. nephrolepis and A. holophylla and some other representatives of the genus Abies. Biologia. Section Botany 63: 94-99.

Kormuták, A., M. Ostrolucká, B. Vooková, A. PreŤová and M. FEC̆KOvÁ (2005): Artificial hybridization of Pinus sylvestris L. and Pinus mugo Turra. Acta Biologica Cracoviensia. Series Botanica 47: 129-134.

KoROPACHINSKIY, I. YU. (1992): Botanical, geographical and forestry aspects of natural hybridization of woody plants. Lesovedenie 2: 3-10. (In Russian)

KoROPACHINSKIY, I. YU. and L. I. MILYUTIN (1979): Natural hybridization of forest trees in USSR and it economic importance. Izvestia SB of USSR Academy of Sciences. Seria biologicheskih nauk 1: 29-36. (In Russian)

KoRopachinskiY, I. YU. and L. I. MilyUTin (2006): Natural hybridization of woody plants. Geo, Novosibirsk. (In Russian)
KRIEBEL, H. B. (1972): Embryo development and hybridity barriers in the white pines (Section Strobus). Silvae Genet. 21: 39-44.

LEDIG, F. T. (1998): Genetic variation in Pinus, pp. 251-280 in Ecology and Biogeography of Pinus, edited by D.M. Richardson, Cambridge University Press.

LeWANDowski, A. and M. WiśniewskA (2006): Short note: crossability between Pinus uliginosa and its putative parental species Pinus sylvestris and Pinus mugo. Silvae Genet. 55: 52-54.

Liston, A., M. Parker-Defeniks, J. V. Syring, A. Willyard and R. CRONN (2007): Interspecific phylogenetic analysis enhances intraspecific phylogeographical inference: a case study in Pinus lambertiana. Mol. Ecol. 16: 3926-3937.

Major, J. E., A. Mosseler, K. H. Johnsen, O. P. Rajora, D. C. BARSI, K.-H. KIM, J.-M. PARK and M. CAMPBELL (2005): Reproductive barriers and hybridity in two spruces, Picea rubens and Picea mariana, sympatric in eastern North America. Can. J. Bot. 83: 163-175.

Matos, J. A. and B. A. SchaAl (2000): Chloroplast evolution in the Pinus montezumae complex: a coalescent approach to hybridization. Evolution 54: 1218-1233.

MCWilliam, J. R. (1959): Interspecific incompatibility in Pinus. Amer. J. Bot. 46: 425-433.

MolozhniKov, V. N. (1975): Siberian dwarf pine in mountain landscape of Northern Baikal region. Moscow, Nauka. 203 p. (In Russian)

Nekrasova, T. P. (1972): Biological foundation of Siberian stone pine seed bearing. Nauka, Novosibirsk. (In Russian)

Owens, J. N. and M. Molder (1977): Seed-cone differentiation and sexual reproduction in western white pine (Pinus monticola). Can. J. Bot. 55: 2574-2590.

Petrova, E. A., S. N. Goroshkevich, D. V. Politov, M. M. Belokon, A. G. Popov and G. V. VAsilyeva (2007): Seed production and genetic structure of populations in natural hybrid zone of Siberian stone pine and Siberian dwarf pine. Khvoynyye borealnoy zony 24: 329-335. (In Russian)

PozDNYAKOV, L. K. (1952): Tree form of Siberian dwarf pine. Botanicheskij Journal 37(5): 688-691. (In Russian)

Politov, D. V., M. M. Belokon, O. P. Maluchenko, Y. S. Belokon, V. N. Molozhnikov, L. E. Mejnartowicz and K.V. KRUTOVsKY (1999): Genetic evidence of natural hybridization between Pinus sibirica Du Tour and P. pumila (Pall.) Regel. For. Genet. 6: 41-48.

RIESEBERG, L. H. (2001) Chromosomal rearrangements and speciation. Trends in ecology and evolution 16: 351-358.

RIESEBERG, L. H. (1997): Hybrid origins of plant species. Ann. rev. ecol. syst. 28: 359-389.

RIEseberG, L. H. and S. E. CARney (1998): Plant hybridization. New Phytol. 140: 599-624.

Senjo, M., K. Kimura, Y. Watano, K. Ueda and T. ShimizU (1999): Extensive mitochondrial introgression from Pinus pumila to $P$. parviflora var. pentaphylla (Pinaceae). J. Plant Res. 112: 97-105.

ShCherbakova, M. A. (1965): Detection of quality conifer seed by X-ray analysis. Forest and Timber Institute SB of USSR Academy of Sciences, Krasnoyarsk. (In Russian)

Titov, E.V. (1977): Trial in crossing Pinus sibirica with other pines in the NE Altai. Lesovedenie 4: 81-87. (In Russian) 